\title{
Hypoxia promotes radioresistance of CD133-positive Hep-2 human laryngeal squamous carcinoma cells in vitro
}

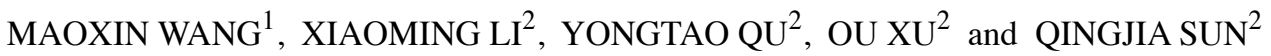 \\ ${ }^{1}$ Otolaryngology Department, Fuzhou General Hospital of PLA, Fuzhou, Fujian 350025; ${ }^{2}$ Otolaryngology Department, \\ Bethune International Peace Hospital of PLA, Shijiazhuang, Hebei 050082, P.R. China
}

Received February 18, 2013; Accepted April 5, 2013

DOI: $10.3892 /$ ijo.2013.1929

\begin{abstract}
Hypoxia promotes the radioresistance of laryngeal carcinomas and CD133 is one of the markers expressed by tumor-initiating, human laryngeal carcinoma cells. In order to investigate whether CD133-positive Hep-2 cells exhibit a radioresistant phenotype and to determine whether hypoxia promotes this phenotype, we performed a series of experiments. Hep-2 cells, and Hep-2 cells stably expressing hypoxia-inducible factor (HIF)-targeted small interfering RNA (siRNA) were cultured under hypoxic and normoxic conditions and were treated with varying doses of $\gamma$-rays $(0,5,10,15$ and $20 \mathrm{~Gy})$. MTT and cell cycle assays were subsequently performed. Using fluorescenceactivated cell sorting (FACS), CD133-positive Hep-2 cells and CD133-positive HIF-siRNA Hep-2 cells were isolated. These cells were grown as spheres under hypoxic and normoxic conditions for MTT and soft agar colony formation assays. The expression levels of DNA-dependent protein kinase catalytic subunit (DNA-PKcs), survivin, p53 and ataxia-telangiectasia mutated (ATM) were also assayed using flow cytometry. The data showed that the growth of Hep-2 cells exposed to hypoxic conditions and treated with $10 \mathrm{~Gy}$ radiation (group A) was less compared to that of groups B-D $(\mathrm{P}<0.05)$. In addition, more cells in group A were arrested in the G1 phase of the cell cycle compared to groups $\mathrm{B}-\mathrm{D}(\mathrm{P}<0.05)$. The percentage of $\mathrm{CD} 133^{+}$ cells detected after radiation increased and was the highest for group A $(\mathrm{P}<0.05)$. In sphere formation assays, significantly more $\mathrm{CD} 133^{+}$cells grew in spheres than $\mathrm{CD} 133^{-}$cells $(\mathrm{P}<0.001)$. Moreover, sphere formation was the highest for CD133 ${ }^{+} \mathrm{Hep}-2$ cells grown under hypoxic conditions and exposed to irradiation (group E) $(\mathrm{P}<0.05)$. Lastly, expression of DNA-PKcs and survivin for group $\mathrm{E}$ was the highest $(\mathrm{P}<0.05)$, while ATM and p53 levels remained largely unchanged $(\mathrm{P}>0.05)$. In conclusion,
\end{abstract}

Correspondence to: Professor Xiaoming Li, Otolaryngology Department, Bethune International Peace Hospital of PLA, Zhongshanxi Road, Shijiazhuang, Hebei 050082, P.R. China E-mail: xmlimo@126.com

Key words: laryngeal squamous cancer, hypoxia inducing factor-1 $\alpha$, CD133, cancer stem cells, radiotherapy, radioresistance, DNA repair, hypoxia
CD133-positive Hep-2 cells exhibited a radioresistant phenotype that was enhanced with hypoxia. Furthermore, an increase in DNA-PK activity was associated with this enhancement.

\section{Introduction}

Laryngeal carcinomas are malignant tumors which are difficult to cure. Traditionally, patients with laryngeal cancer are treated with surgery, radiotherapy alone, or adjuvant treatments. The effects of radiation therapy have been found to be reliable and adverse reactions can be readily observed. However, radiation therapy is only associated with a relatively good efficacy when it is applied to radiation-sensitive patients. Moreover, treatment failures have occurred even with early stage cancers (1). Therefore, radioresistance of laryngeal cancers represents a serious problem and determining the mechanism(s) mediating this radioresistance is critical.

Research of disease mechanisms over the past couple of years has shown that cancer stem cells (CSCs) can exhibit a radioresistant phenotype. Moreover, a 'cancer stem cell' theory has gained interest in the field of oncology, where CSCs are proposed to possess a self-renewal property typical of normal stem cells. Correspondingly, despite tumor tissues containing very few CSCs which rarely divide, tumors are still able to produce rapidly proliferating daughter cells. Previous studies have demonstrated the existence of CSCs in a variety of tumors (2-6).

Furthermore, expression of CD133 has been used to define the CSC populations in brain, lung, pancreatic, liver, prostate, gastric, colorectal and head and neck cancers (7-14). CD133 ${ }^{+}$ tumors have also been shown to establish more efficiently in immunocompromised mice than CD133- tumors (15). In addition to these stem cell properties, CSCs also display a high resistance to radiation and conventional chemotherapy. For example, Bao et al (16) reported that $\mathrm{CD} 133^{+} \mathrm{CSC}$ s contributed to glioma radioresistance through preferential activation of DNA damage checkpoint responses and an increased capacity for DNA repair. In brain glioblastomas, Liu et al (17) reported that $\mathrm{CD}_{133}{ }^{+} \mathrm{CSC}$ s exhibited strong chemoresistance due to higher expression of ABCG2 and MGMT. These studies strongly support the cancer stem cell theory that CSCs are the underlying cause of radioresistance and chemoresistance exhibited by tumors. 
CSCs grow in a 'niche', a microenvironment that is composed of a specialized vascular bed of endothelial cells, associated cells of mesenchymal origin and extracellular matrix components (18). The secretion of factors within this niche can lead to the regulation, or maintainance, of a CSC phenotype. Furthermore, these factors can affect tumor invasion, metastasis and response to therapy $(19,20)$. Often, the tumor microenvironment also includes hypoxic conditions, whereby expression of hypoxia inducible factor- $1 \alpha$ (HIF-1 $\alpha)$ is induced. Induction of HIF-1 $\alpha$ has been shown to correlate with an increase in the ratio of CSCs present in a tumor (21) and to modulate specific stem cell effectors, including Notch, Wnt and Oct4, which control stem cell proliferation, differentiation and pluripotency (22). Moreover, HIF-1 $\alpha$ has been shown to enhance radioresistance. For example, a selective HIF-1 $\alpha$ inhibitor enhanced the sensitivity of malignant gliomas to radiotherapy (23). However, it remains to be determined whether radioresistance of laryngeal cancers are caused by CSCs and whether hypoxia affects CSCs. Therefore, these two aspects were examined using Hep-2 cells in vitro.

\section{Materials and methods}

Cell lines and culturing. Hep-2 cells were purchased from the Institute of Biochemistry and Cell Biology, SIBS, CAS. HIF-1 $\alpha$-silenced Hep- 2 cells which stably express HIF-RNAi were obtained from the Bethune International Hospital (38). Both cell types were cultured in RPMI-1640 medium containing $10 \%$ fetal calf serum (Sijiqing Co., China) in $25 \mathrm{ml}$ flasks. For normoxic conditions, cells were maintained in $21 \% \mathrm{O}_{2}$, while hypoxic conditions included the incubation of cells with $1 \% \mathrm{O}_{2}$. Media was changed every 1-2 days and when cells reached $80-90 \%$ confluency, they were passaged or used.

Treatment groups and irradiation. Cells were divided into four groups: groups A and B included Hep-2 cells cultured under hypoxic or normoxic conditions, respectively; while groups C and D included HIF-siRNA Hep-2 cells cultured under hypoxic and normoxic conditions, respectively. Delivery of irradiation was conducted under ambient conditions with different radiation dosages applied (0, 5, 10, 15 and $20 \mathrm{~Gy})$. All irradiations were performed using a ${ }^{60} \mathrm{Co}$ unit (FCC-7000, Shangdong Xinhua Medical Instrument Co. Ltd., China) with a source skin distance (SSD) of $75 \mathrm{~cm}$, a radiation area of $20 \times 20 \mathrm{~cm}^{2}$ and a dose rate of $486 \mathrm{cGy} / \mathrm{min}$. Following irradiation, cells received fresh media.

MTT assays. MTT was dissolved in phosphate-buffered saline (PBS) and adjusted to a final concentration of $5 \mathrm{mg} / \mathrm{ml}$. For MTT assays, Hep-2 cells (4x103/well) were cultured in 96-well plates under hypoxic and normoxic conditions. After $36 \mathrm{~h}$, cells were exposed to varying doses of irradiation while being maintained under hypoxic and normoxic conditions. After 12, 24, 36 and $48 \mathrm{~h}, 20 \mu \mathrm{l}$ MTT was added to each well. After an additional $4 \mathrm{~h}$ at $37^{\circ} \mathrm{C}$, culture media was removed and $150 \mu \mathrm{l}$ DMSO was added. Plates were swirled gently in the dark for $10 \mathrm{~min}$ at RT. Absorbance values at $490 \mathrm{~nm}$ (A490) for each well were then measured using an enzyme-linked immunosorbent detector (Model 550, Bio-Rad, Hercules, CA,
USA). Based on these data, cell growth inhibition ratios were calculated according to the following formula: cell growth inhibition ratio $=[$ control group $(0$ Gy group $)$ A value experimental group (each dose point group) A value]/control group A value x $100 \%$. Data were plotted with absorbed doses along the $\mathrm{x}$-axis and inhibition ratios reported along the $\mathrm{y}$-axis.

Flow cytometry to detect cell cycle progression and $\mathrm{CD} 133^{+}$ Hep-2 cells. After Hep-2 cells were cultured for $36 \mathrm{~h}$ under hypoxic or normoxic conditions, cells received $10 \mathrm{~Gy}$ of irradiation, then were maintained under hypoxic and normoxic conditions. After $24 \mathrm{~h}$, cells were adjusted to a concentration of $1 \times 10^{6}$ cells $/ \mathrm{ml}$ with Buffer 1 (PBS $/ 0.5 \%$ bovine serum albumin (BSA)/2 mM EDTA). Cells were then fixed with $70 \%$ alcohol for $18 \mathrm{~h}$. Ethanol was removed by centrifugation and cells were stained with $50 \mathrm{mg} / \mathrm{ml}$ propidium iodide (PI, Sigma Chemical Co., St. Louis, MO, USA) at $4^{\circ} \mathrm{C}$ for $30 \mathrm{~min}$ before cell circle were detected. To detect the $\mathrm{CD} 133^{+}$cell population, cells were stained with a PE-conjugated CD133 mouse antihuman monoclonal antibody (Miltenyi Biotechnology Corp., Germany) or a PE-conjugated mouse anti-human IgG (control) at $4^{\circ} \mathrm{C}$. After $30 \mathrm{~min}$, cells were washed twice with Buffer 1, were resuspended in $500 \mu \mathrm{l}$ Buffer 1 and were analyzed using a FACS flow cytometer and CellQuest software (BD Biosciences, San Jose, CA, USA).

Fluorescence-activated cell sorting. CD133+ cells were isolated from Hep-2 cells and HIF-siRNA Hep-2 cells and were cultured. For staining, Hep-2 cells $\left(1 \times 10^{8}\right)$ were adjusted to a concentration of $1 \times 10^{7}$ cells $/ \mathrm{ml}$ with Buffer 1 and incubated with PE-conjugated CD133 mouse anti-human monoclonal antibody (Miltenyi Biotechnology Corp.) for $30 \mathrm{~min}$ at $4^{\circ} \mathrm{C}$. After cells were washed twice with Buffer 1, cells were resuspended in $10 \mathrm{ml}$ Buffer 1 . FACS of $\mathrm{CD} 133^{+}$and $\mathrm{CD}^{-} 33^{-}$cells was performed using a Cytomation ArialI cytometer (BD Biosciences). Cells incubated with PE-conjugated mouse antihuman $\mathrm{IgG}$ were used as controls and the top $25 \%$ of the most brightly stained cells were isolated as $\mathrm{CD}_{133^{+}}$cells.

Culturing of $\mathrm{CD} 133^{+}$cells, sphere formation assays and treatment groups. CD133+ cells were cultured in serum-free RPMI-1640 medium (SFM), containing $0.5 \%$ bovine serum albumin (BSA), $100 \mathrm{ng} / \mathrm{ml}$ epidermal growth factor (EGF), $40 \mathrm{ng} / \mathrm{ml} \beta$-FGF, $5 \mu \mathrm{g} / \mathrm{ml}$ insulin, $100 \mathrm{IU} / \mathrm{ml}$ penicillin, $100 \mu \mathrm{g} / \mathrm{ml}$ streptomycin and $5 \mathrm{ng} / \mathrm{ml}$ leukemia inhibitory factor (LIF). Between 1 and 3 weeks later, cultures were monitored for sphere formation. For passaging of the spheres, medium was centrifuged, incubated with trypsin, then single cell suspensions were obtained with mechanical dissociation. After cells were resuspended in SFM $\left(2 \times 10^{5}\right.$ cells/ml), CD133 ${ }^{+}$ cells were divided into groups E-H: i) in group E, Hep-2 cells were cultured under hypoxic conditions; ii) in group F, Hep-2 cells were cultured under normoxic conditions; iii) in group G, HIF-siRNA Hep-2 cells were cultured under hypoxic conditions; and iv) in group H, HIF-siRNA Hep-2 cells were cultured under normoxic conditions. After 36 h, all groups received 10 Gy irradiation.

MTT assay of $\mathrm{CD} 133^{+}$cells. For MTT assays of $\mathrm{CD} 133^{+}$cells, the MTT protocol described above was used, except that the 
media used was serum-free and the 96-well plates were centrifuged and medium was disgarded before DMSO was added.

Soft agar colony formation assays. Colony formation was evaluated using soft-agar plate assays. Briefly, CD133+ cells (100 cells/well) from each group were embedded in $0.3 \%$ agar gel containing RPMI-1640 medium and 20\% fetal calf serum in 6 -well plates precoated with $0.5 \%$ agar gel containing RPMI-1640/20\% FCS. After 36 h of hypoxic or normoxic culture conditions, cells were treated with 10 Gy irradiation. Fourteen days later, $0.5 \mathrm{ml}$ MTT was added to each well, plates were incubated for $30 \mathrm{~min}$, then colonies containing $\geq 50$ cells were counted. These assays were performed in duplicate with each sample assayed in triplicate.

Flow cytometry to detect protein expression. The four groups of CD133 ${ }^{+}$Hep-2 and HIF-siRNA Hep- 2 cells were cultured for $36 \mathrm{~h}$, then treated with $10 \mathrm{~Gy}$ irradiation. After an additional $24 \mathrm{~h}$ of culturing, cells $\left(2 \times 10^{5}\right)$ were washed twice with Buffer 1 (PBS/0.5\% BSA) then were re-suspended with fixation and permeabilization solution (B\&D Biosciences Pharmingen) and incubated for $20 \mathrm{~min}$. Cells were then washed with Buffer 2 (Perm/Wash ${ }^{\mathrm{TM}}$ buffer solution; B\&D Biosciences Pharmigen) and incubated with the following primary antibodies diluted in Buffer 2: mouse anti-human p53, survivin (Santa Cruz Biotechnology, Inc. Santa Cruz, CA, USA), DNA-dependent protein kinase, catalytic subunit (DNA-PKcs) (Neomarker, USA), ataxia-telangiectasia mutated (ATM) (Biovision, Mountain View, CA, USA). After $1 \mathrm{~h}$ at $4^{\circ} \mathrm{C}$, cells were washed twice with Buffer 2, then were resuspended in $50 \mu 1$ Buffer 2, to which DyLight ${ }^{\mathrm{TM}} 488$ conjugated goat anti-mouse IgG (Multisciences Biotech Corp., China) was added. Samples were incubated in the dark for $30 \mathrm{~min}$ at $4^{\circ} \mathrm{C}$. Following two washes with Buffer 1, samples were analyzed using a FACS flow cytometer and CellQuest software (BD Biosciences).

Statistical analysis. Data are expressed as the mean \pm standard deviation (SD). All statistical analyses were performed using SPSS15.0 software. Factorial and linear correlation analyses were applied to values measured by MTT assays, apoptosis rates and DNA-PKcs, ATM, p53 and survivin proteins. $\mathrm{P}<0.05$ was considered statistically significant.

\section{Results}

Confirmation of HIF-1 $\alpha$ expression and validation of in vitro model. Two populations of human laryngeal carcinoma cells were assayed under hypoxic and normoxic conditions in vitro. The first population included Hep-2 cells, representing groups A and B, respectively. The second population included HIF-siRNA Hep-2 which stably express HIF-1 $\alpha$-targeted siRNA, representing groups $\mathrm{C}$ and $\mathrm{D}$, respectively. To validate the hypoxic and normoxic conditions employed in this study, levels of HIF-1 $\alpha$ were detected in groups A-D by western blotting. Consistent with the role for HIF-1 $\alpha$ during hypoxia, higher levels of HIF-1 $\alpha$ were detected in Hep-2 cells cultured under hypoxic conditions (e.g., group A) versus normoxic conditions (e.g., group B). In contrast, HIF-siRNA Hep-2 cells did not have detectable levels of HIF-1 $\alpha$ expressed by either group C or D cells (Fig. 1).

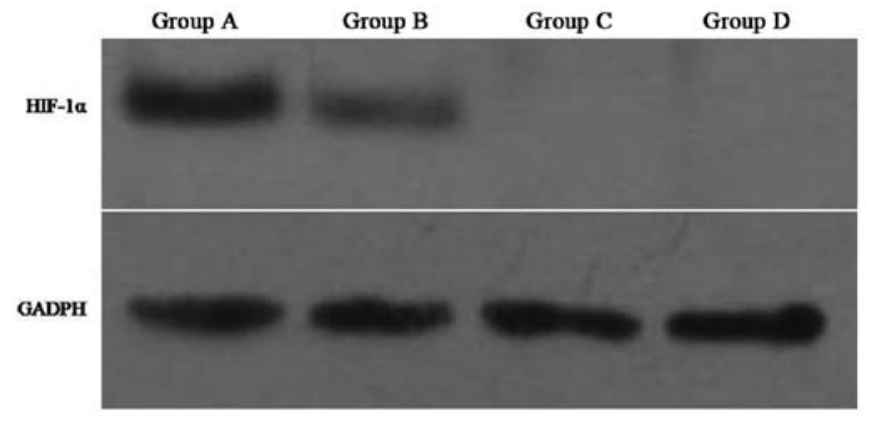

Figure 1. Expression of HIF-1 $\alpha$ was detected by western blotting. Extracts from groups A-D were analyzed by western blotting and higher levels of HIF-1 $\alpha$ were detected in Hep-2 cells maintained under hypoxic and normoxic conditions (groups A and B, respectively), compared to undetectable levels of HIF-1 $\alpha$ detected in HIF-siRNA Hep-2 cells maintained under hypoxic and normoxic conditions (groups $\mathrm{C}$ and $\mathrm{D}$, respectively). These differences in expression were significant $(\mathrm{P}<0.05)$. Detection of GAPDH was used as a loading control.
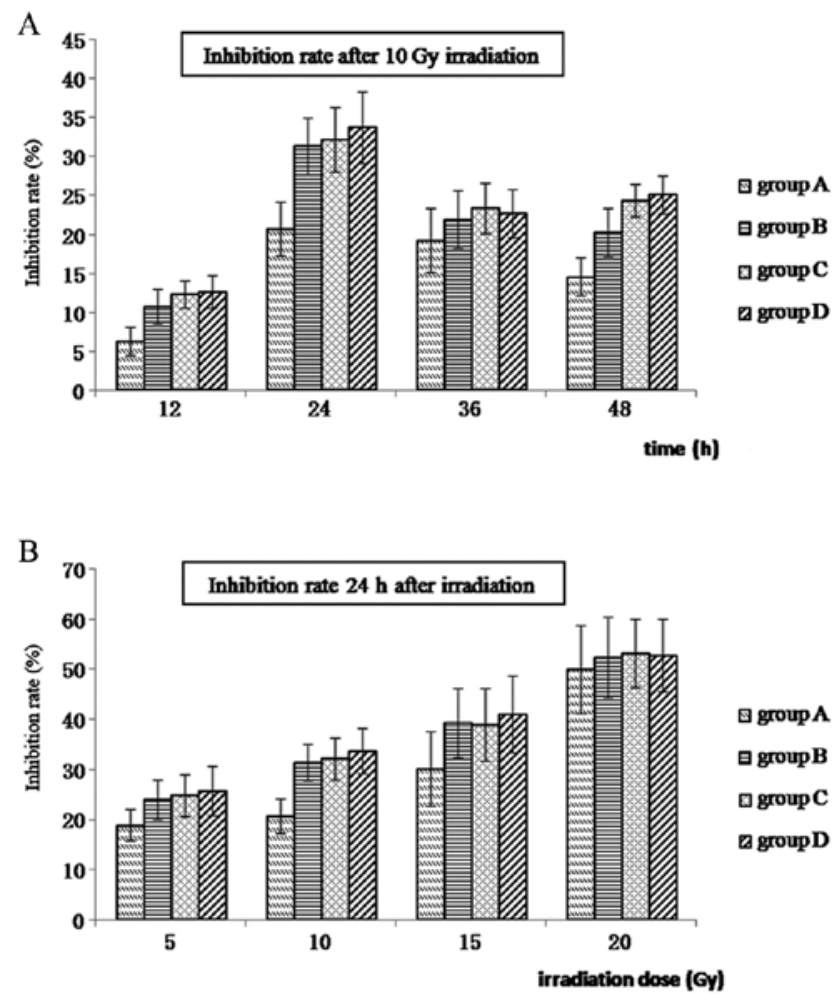

Figure 2. Growth inhibition ratios for groups A-D were detected using MTT assays and are presented in a histogram. The growth inhibition ratio for each group was the highest at the $24 \mathrm{~h}$ time-point following $10 \mathrm{~Gy}$ irradiation. Ratios also increased in a radiation dose-dependent manner (A). Group A had the lowest growth inhibition ratio of the four groups at every dose and time-point. However, $24 \mathrm{~h}$ after treatment with $10 \mathrm{~Gy}$ radiation, the growth inhibition ratio for group A showed the greatest difference $(B)(P<0.05)$.

Growth inhibition of Hep-2 cells following treatment with different doses of radiation. To examine whether Hep-2 cells exhibit a radioresistant phenotype that is affected by hypoxia, cell groups A-D were subjected to various doses of irradiation $(0,5,10,15$ and $20 \mathrm{~Gy})$. Following irradiation, cells received fresh media and cell growth was monitored using MTT assays. As shown in Fig. 2, growth inhibition ratios for groups A-D 
Table I. Growth inhibition ratios for the treatment groups.

\begin{tabular}{|c|c|c|c|c|c|c|c|c|}
\hline \multirow[b]{2}{*}{ Cell group } & \multicolumn{4}{|c|}{ Radiation dose $\mathrm{a}^{\mathrm{a}}$} & \multicolumn{4}{|c|}{ Time-point following $10 \mathrm{~Gy}$ irradiation } \\
\hline & $5 \mathrm{~Gy}$ & $10 \mathrm{~Gy}$ & $15 \mathrm{~Gy}$ & 20 Gy & $12 \mathrm{~h}$ & $24 \mathrm{~h}$ & $36 \mathrm{~h}$ & $48 \mathrm{~h}$ \\
\hline A & $18.9 \pm 3.1$ & $20.7 \pm 3.4$ & $30.1 \pm 7.4$ & $50.0 \pm 8.8$ & $6.3 \pm 1.9$ & $20.7 \pm 3.4$ & $19.3 \pm 4.1$ & $14.6 \pm 2.42$ \\
\hline B & $24.0 \pm 3.9$ & $31.4 \pm 3.7$ & $39.4 \pm 7.0$ & $52.4 \pm 8.1$ & $10.8 \pm 2.3$ & $31.4 \pm 3.7$ & $21.9 \pm 3.7$ & $20.3 \pm 3.1$ \\
\hline $\mathrm{C}$ & $24.9 \pm 4.1$ & $32.2 \pm 4.1$ & $39.0 \pm 7.3$ & $53.2 \pm 6.8$ & $12.3 \pm 1.7$ & $32.2 \pm 4.1$ & $23.4 \pm 3.3$ & $24.4 \pm 2.1$ \\
\hline D & $25.7 \pm 5.0$ & $33.8 \pm 4.5$ & $41.1 \pm 7.7$ & $52.8 \pm 7.2$ & $12.7 \pm 2.1$ & $33.8 \pm 4.5$ & $22.7 \pm 3.2$ & $25.1 \pm 2.4$ \\
\hline
\end{tabular}

Group A/B, Hep-2 cells grown under hypoxic/normoxic conditions. Group C/D, HIF-siRNA Hep-2 cells grown under hypoxic/normoxic conditions. ${ }^{\mathrm{a}}$ Ratios were obtained $24 \mathrm{~h}$ after irradiation.

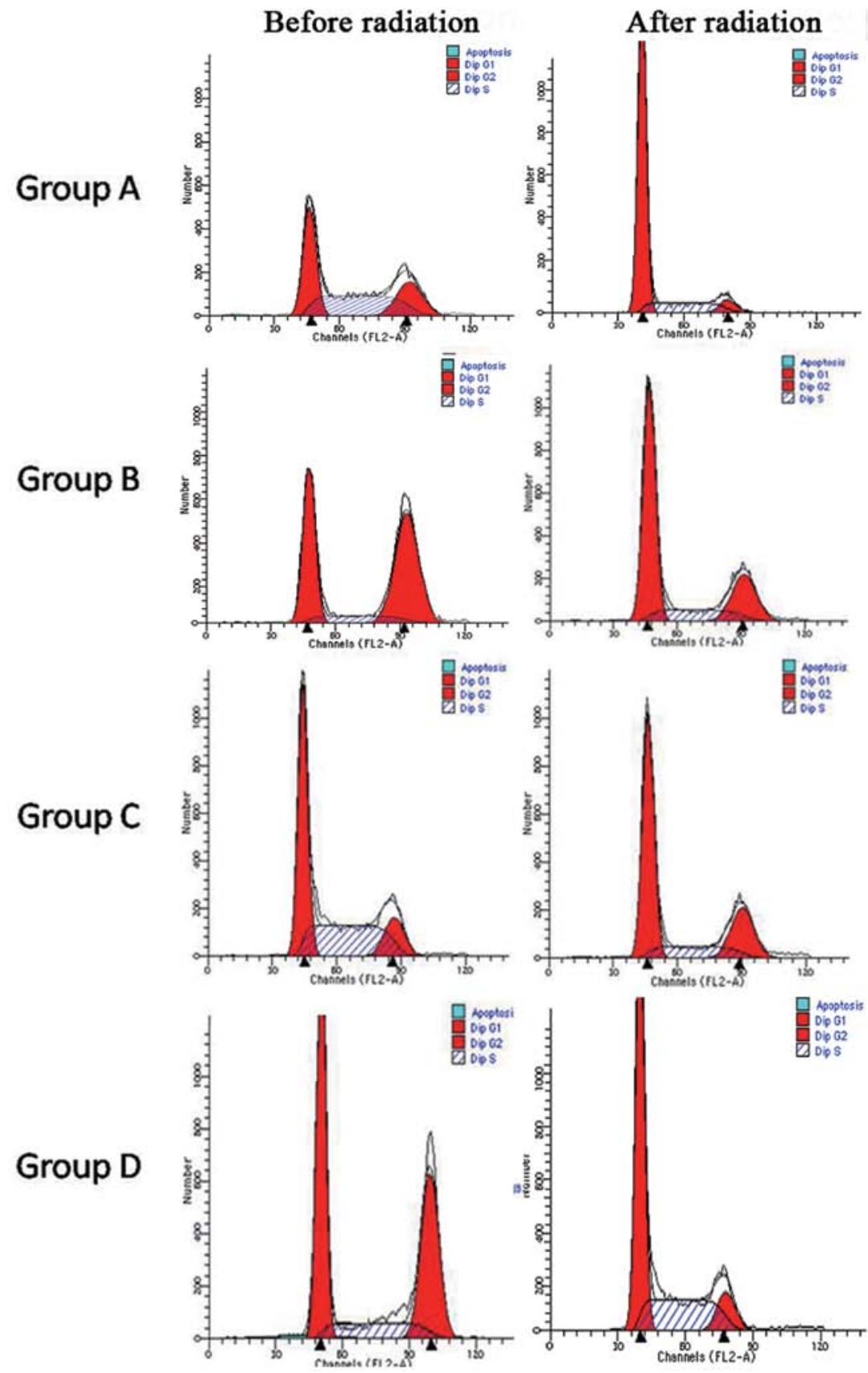

Figure 3. Cell cycle progression for groups A-D was measured using flow cytometry. The percentage of cells in the G1 phase following irradiation was observed to increase for groups A-D, while the percentage of cells in the G2/S phase decreased. Among groups A-D, the percentage of cells in the G1 phase and the G2/S phase for group A were higher and lower, respectively, than groups B-D following irradiation $(\mathrm{P}<0.05)$. However, differences between groups $B, C$ and $D$ were not significant. 

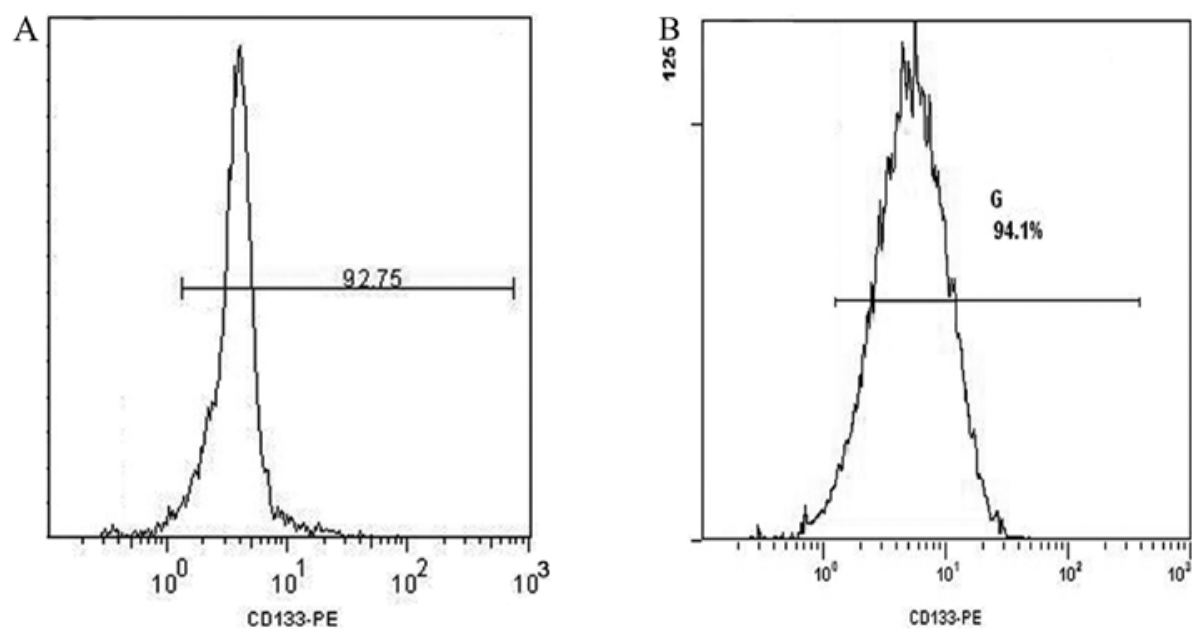

Figure 4. Purity of $\mathrm{CD}_{133^{+}}$cells following fluorescence-activated cell sorting of Hep-2 cells (A) and HIF-siRNA Hep-2 cells (B).

are shown at various time-points following the application of $10 \mathrm{~Gy}$ irradiation (Fig. 2A) and $24 \mathrm{~h}$ after different doses of radiation (Fig. 2B). Growth of Hep-2 cells was observed to be radiation dose-dependent, with higher levels of growth inhibition observed with higher levels of irradiation. Moreover, the greatest difference in the ratio of growth inhibition was observed at the $24 \mathrm{~h}$ time-point following $10 \mathrm{~Gy}$ irradiation $(\mathrm{P}<0.05)$. Growth inhibition was also the lowest for hypoxic Hep-2 cells (group A) at each dose and time-point (Fig. 2 and Table I).

Cell cycle distribution for $C D 133^{+}$Hep- 2 cells in groups A-D $24 \mathrm{~h}$ after irradiation. Groups A-D were cultured for $36 \mathrm{~h}$ under hypoxic or normoxic conditions before cells were treated with $10 \mathrm{~Gy}$ of radiation. Cells were then maintained under hypoxic and normoxic conditions until cell cycle assays were performed. Cells were co-stained with PI and PE-conjugated CD133 mouse anti-human monoclonal antibody. For all four groups following irradiation, the percentage of cells in the G1 phase increased, while the percentage of cells in the G2/S phase decreased. In groups A and B, a 4- and 2-fold increase in cells in the G1 phase after radiation was observed, respectively. In contrast, there was no significant increase in the G1 population for groups $\mathrm{C}$ and D. For the G2/S population, a decrease was observed following exposure to radiation for groups B and D. Among the four groups, hypoxic Hep-2 cells (group A) maintained most of the cells in the G1 phase $(\mathrm{P}<0.05)$ (Fig. 3 and Table II).

The percentage of $\mathrm{CD}_{133^{+}}$cells in groups A-D before and after irradiation were also detected by flow cytometry. These percentages included: 1.5 versus $9.9 \%$ for group A, 1.0 versus $3.3 \%$ for group B, 0.8 versus $2.7 \%$ for group C and 0.7 versus $2.5 \%$ for group $\mathrm{D}$, respectively, in each case. Hep-2 cells cultured under hypoxic conditions (e.g., group A) exhibited a significant difference in the $\mathrm{CD}_{133}{ }^{+}$population in response to irradiation $(\mathrm{P}<0.05)$. In contrast, the percentage of $\mathrm{CD}_{133^{+}}$cells in groups B-D did not significantly differ (Table III)

Isolation of $\mathrm{CDI}^{3} 3^{+}$cells using fluorescence-activated cell sorting (FACS) and sphere formation assays. When Hep-2
Table II. Cell cycle distribution for cell groups A-D.

\begin{tabular}{lccrc}
\hline Cell group & Radiation & G1 $(\%)$ & G2 $(\%)$ & S (\%) \\
\hline A & Before & $30.2 \pm 3.8$ & $26.8 \pm 2.1$ & $40.7 \pm 4.2$ \\
& After & $74.6 \pm 6.4$ & $6.9 \pm 1.5$ & $18.6 \pm 2.1$ \\
B & Before & $36.7 \pm 3.9$ & $50.4 \pm 2.5$ & $12.3 \pm 1.4$ \\
& After & $59.6 \pm 5.9$ & $22.2 \pm 2.7$ & $17.1 \pm 1.3$ \\
C & Before & $45.2 \pm 3.8$ & $15.7 \pm 2.0$ & $41.1 \pm 5.1$ \\
& After & $58.3 \pm 4.3$ & $23.2 \pm 1.9$ & $16.4 \pm 1.4$ \\
D & Before & $45.1 \pm 4.4$ & $37.3 \pm 3.6$ & $16.0 \pm 1.9$ \\
& After & $57.7 \pm 4.8$ & $11.4 \pm 0.8$ & $32.3 \pm 3.0$
\end{tabular}

Group A/B, Hep-2 cells grown under hypoxic/normoxic conditions. Group C/D, HIF-siRNA Hep-2 cells grown under hypoxic/normoxic conditions.

Table III. CD133+ cell ratio for cell groups A-D.

\begin{tabular}{lcccc}
\hline Radiation & Group A & Group B & Group C & Group D \\
\hline Before & $1.4 \pm 0.1$ & $1.0 \pm 0.08$ & $0.8 \pm 0.06$ & $0.7 \pm 0.06$ \\
After & $9.9 \pm 1.1$ & $3.3 \pm 0.2$ & $2.7 \pm 0.2$ & $2.5 \pm 0.1$ \\
\hline
\end{tabular}

Group A/B, Hep-2 cells grown under hypoxic/normoxic conditions. Group C/D, HIF-siRNA Hep-2 cells grown under hypoxic/normoxic conditions.

cells and HIF-siRNA Hep- 2 cells were sorted for $\mathrm{CD} 133^{+}$cells using FACS, $\sim 1 \times 10^{6}$ cells were obtained with a cell purity of 92.8 and $94.1 \%$, respectively (Fig. 4). These two sets of cells were then cultured for 2 weeks in SFM and the phenotype of the spheres that formed are shown in Fig. 5. When these two sets of spheres were digested with $0.25 \%$ zymine, the resulting single cell suspensions were also analyzed by FACS and the 

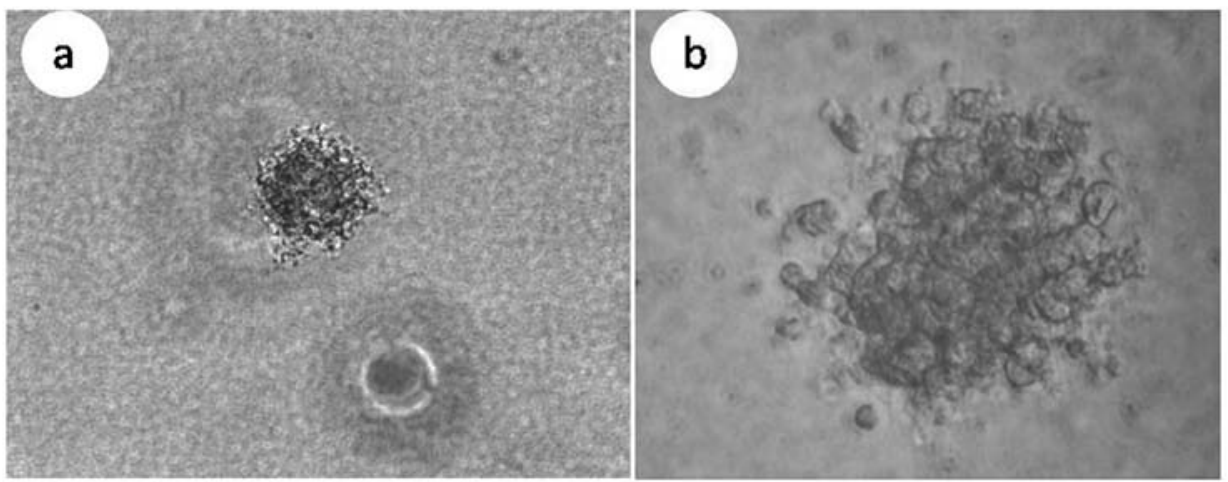

Figure 5. Sphere formation assays performed 1 week after $\mathrm{CD}_{133^{+}}$cells were isolated and cultured. Images were obtained using an inverted phase contrast microscope with magnification $\mathrm{x} 100$ and $\mathrm{x} 200$, respectively.

Table IV. Growth inhibition ratios for $\mathrm{CD} 133^{+}$cells in groups E-H.

\begin{tabular}{|c|c|c|c|c|c|c|c|c|}
\hline \multirow[b]{2}{*}{ Cell group } & \multicolumn{4}{|c|}{ Radiation dose $\mathrm{e}^{\mathrm{a}}$} & \multicolumn{4}{|c|}{ Time-point following 10 Gy irradiation } \\
\hline & 5 Gy & $10 \mathrm{~Gy}$ & 15 Gy & 20 Gy & $12 \mathrm{~h}$ & $24 \mathrm{~h}$ & $36 \mathrm{~h}$ & $48 \mathrm{~h}$ \\
\hline E & $5.60 \pm 1.78$ & $19.83 \pm 1.18$ & $32.08 \pm 2.08$ & $35.15 \pm 2.11$ & $27.11 \pm 1.12$ & $21.69 \pm 1.60$ & $28.83 \pm 2.15$ & $27.43 \pm 1.50$ \\
\hline $\mathrm{F}$ & $6.54 \pm 1.50$ & $29.16 \pm 2.37$ & $37.81 \pm 2.13$ & $41.06 \pm 3.27$ & $30.22 \pm 1.45$ & $32.17 \pm 1.49$ & $35.49 \pm 1.38$ & $32.43 \pm 1.87$ \\
\hline $\mathrm{G}$ & $9.48 \pm 1.48$ & $31.46 \pm 1.32$ & $37.43 \pm 1.84$ & $40.71 \pm 1.78$ & $32.14 \pm 2.10$ & $34.55 \pm 2.24$ & $37.34 \pm 2.49$ & $36.88 \pm 2.28$ \\
\hline $\mathrm{H}$ & $9.90 \pm 0.08$ & $31.69 \pm 3.93$ & $36.90 \pm 2.17$ & $41.18 \pm 1.09$ & $31.33 \pm 1.98$ & $36.21 \pm 2.51$ & $37.96 \pm 3.08$ & $38.05 \pm 3.20$ \\
\hline
\end{tabular}

Group A/B, Hep-2 cells grown under hypoxic/normoxic conditions. Group C/D, HIF-siRNA Hep-2 cells grown under hypoxic/normoxic conditions. ${ }^{2}$ Ratios were obtained $24 \mathrm{~h}$ after irradiation.

percentage of $\mathrm{CD}_{133}{ }^{+}$cells detected were 88.3 and $89.4 \%$, respectively.

Viability of $\mathrm{CD} 133^{+}$cells. The $\mathrm{CD} 133^{+}$cells obtained following FACS of the Hep-2 spheres and HIF-siRNA Hep-2 spheres, were divided into groups E-H. In groups E and F, Hep-2 cells were cultured under hypoxic and normoxic conditions, respectively. Similarly, in groups G and H, HIF-siRNA Hep-2 cells were cultured under hypoxic and normoxic conditions, respectively. After $36 \mathrm{~h}$, groups E-H were subjected to various doses of radiation $(0,5,10,15$ and $20 \mathrm{~Gy})$ and subsequently, cells received fresh media at various time-points. Cell growth was then monitored using MTT assays. Growth inhibition was observed to increase in a dose-dependent manner and was the lowest for group $\mathrm{E}$ at each dose and time-point. In addition, the greatest difference in growth inhibition between the four doses was $24 \mathrm{~h}$ after $10 \mathrm{~Gy}$ irradiation $(\mathrm{P}<0.05)$ (Fig. 6 and Table IV).

Sphere formation in soft agar following irradiation. For cell groups E-H, colony formation was also evaluated using soft agar plate assays. In these assays, $\mathrm{CD} 133^{+}$cells and CD133 cells for each group (100 cells/well) were embedded in $0.3 \%$ agar gel, incubated for $36 \mathrm{~h}$ under hypoxic or normoxic culture conditions, then were treated with $10 \mathrm{~Gy}$ radiation. Fourteen days later, $0.5 \mathrm{ml}$ MTT was added to each well and colonies containing $\geq 50$ cells were counted. Sphere formation for $\mathrm{CD}_{133^{+}}$cells was found to be significantly higher
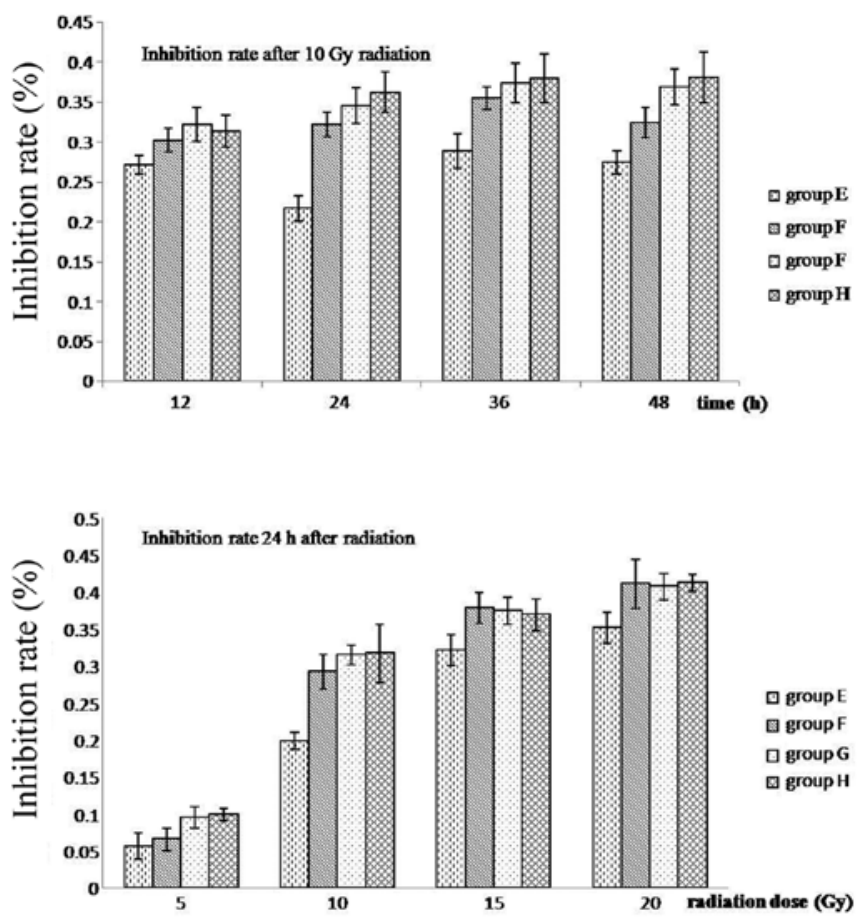

Figure 6. Growth inhibition ratios for groups E-H were detected using MTT assays and are presented in a histogram. The growth inhibition ratio for $\mathrm{CD}_{133^{+}}$cells increased in a radiation dose-dependent manner and was the lowest for group E at every dose and time-point. However, $24 \mathrm{~h}$ after receiving $10 \mathrm{~Gy}$ radiation, the difference in the growth inhibition ratio for group A was the largest $(\mathrm{P}<0.05)$. 
Table V. Sphere formation ratios.

\begin{tabular}{lccc}
\hline Cell group & Before radiation & After radiation & P-value \\
\hline E & $55.0 \pm 4.8$ & $49.4 \pm 5.2$ & $>0.05$ \\
F & $42.8 \pm 6.8$ & $27.1 \pm 6.1$ & $<0.05$ \\
G & $41.3 \pm 7.1$ & $25.7 \pm 5.7$ & $<0.05$ \\
H & $39.2 \pm 6.3$ & $23.4 \pm 6.1$ & $<0.05$ \\
P-value & $<0.05$ & $<0.05$ & \\
\hline
\end{tabular}

Group E/F, Hep-2 cells grown under hypoxic/normoxic conditions. Group G/H, HIF-siRNA Hep-2 cells grown under hypoxic/normoxic conditions.

than that of CD133- cells both before and after irradiation $(\mathrm{P}<0.001)$. Furthermore, sphere formation for hypoxic Hep-2 cells (group E) was greater than that of the other three groups before irradiation. However, after irradiation, sphere formation for group $\mathrm{E}$ was observed to decrease, although this difference was not significant $(\mathrm{P}>0.05)$. In contrast, sphere formation for the other three groups decreased significantly $(\mathrm{P}<0.05)$ (Table V).

Levels of DNA-PKcs, ATM, survivin and p53 in CD133+ cells following irradiation. Expression of DNA-PKcs, ATM, survivin and $\mathrm{p} 53$ were detected in $\mathrm{CD}_{133^{+}}$cells under hypoxic and normoxic conditions, as well as under the same conditions with radiation treatment (10 Gy), using fluorescence-activated flow cytometry. Higher levels of expression were detected for all four proteins in $\mathrm{CD}_{133^{+}}$cells compared with CD133- cells following irradiation $(\mathrm{P}<0.01)$. Furthermore, radiation treatment increased expression of all four proteins in $\mathrm{CD}_{133^{+}}$ groups E-H. In group E, higher levels of DNA-PKes and survivin expression were detected following hypoxia and radiation compared to groups $\mathrm{F}-\mathrm{H}(\mathrm{P}<0.05)$. Moreover, levels of DNA-PKcs and survivin in $\mathrm{CD}_{133^{+}}$cells cultured under hypoxic versus non-hypoxic conditions differed, yet this effect was absent in parallel studies of CD133+ HIF-siRNA cells. For ATM and p53, expression levels did not show significant changes in response to hypoxia ( $\mathrm{P}>0.05)$ (Fig. 7 and Table VI). There was a slight change in ATM levels detected for CD133+ cells cultured under hypoxic conditions and treated with radiation. However, this difference was not significant.

\section{Discussion}

Consistent with previous studies, culturing of Hep-2 cells under hypoxic conditions resulted in higher levels of HIF-1 $\alpha$. Hypoxia-induced radioresistance was also observed in growth inhibition assays, suggesting that downstream targets of HIF-1 $\alpha$, including vascular endothelial growth factor (VEGF), p53 and, may contribute to the radiosensitivity phenotype of Hep-2 cells.

$\mathrm{CD}_{133^{+}}$cells exhibit cancer stem cell-like characteristics (24) and this was confirmed in the present study. However, the percentage of $\mathrm{CD}_{133}{ }^{+}$cells detected in Hep- 2 cells with or without HIF-1 $\alpha$ expression ranged from 0.8 to $1.5 \%$ and this range was somewhat lower than previously reported (24-26). However, the ratio of $\mathrm{CD}_{133^{+}}$cells increased under hypoxic conditions, consistent with previous reports $(27,28)$.

Based on the observation that the ratio of $\mathrm{CD}_{133}{ }^{+}$cells detected in all groups increased following irradiation and the greatest increase was exhibited by Hep-2 cells cultured under hypoxic conditions (group A), we hypothesize that radiation affected a larger number of CD133- cells than $\mathrm{CD}^{-} 33^{+}$cells, with the latter being radioresistant. Furthermore, the highest percentage of $\mathrm{CD} 133^{+}$cells was found in group A both before and after irradiation among groups A-D, suggesting that

Table VI. Levels of DNA-PKcs, ATM, survivin and p53 proteins in CD133+ cells and CD133 ${ }^{+}$HIF-siRNA cells detected by flow cytometry.

\begin{tabular}{lccccc}
\hline & Radiation & Group E & Group F & Group G & Group H \\
\hline DNA-PKcs & Before & $18.5 \pm 2.3$ & $12.7 \pm 4.1$ & $11.1 \pm 2.6$ & $9.6 \pm 1.8$ \\
& After & $80.5 \pm 2.1$ & $54.1 \pm 2.5$ & $48.5 \pm 3.4$ & $44.1 \pm 5.7$ \\
ATM & & & & \\
& Before & $25.0 \pm 1.5$ & $19.4 \pm 1.0$ & $20.2 \pm 2.2$ & $21.1 \pm 1.5$ \\
& After & $55.3 \pm 2.2$ & $52.7 \pm 2.0$ & $45.6 \pm 3.3$ & $47.8 \pm 4.1$ \\
p53 & & & & \\
& Before & $44.5 \pm 4.7$ & $33.6 \pm 3.3$ & $29.6 \pm 2.8$ & $31.1 \pm 3.0$ \\
& After & $74.8 \pm 3.0$ & $71.4 \pm 3.2$ & $68.7 \pm 4.1$ & $70.3 \pm 3.9$ \\
Survivin & & & & & $29.2 \pm 3.7$ \\
& Before & $35.8 \pm 2.4$ & $30.1 \pm 3.1$ & $27.1 \pm 3.2$ & $67.1 \pm 5.6$ \\
\hline
\end{tabular}

Group E/F, CD133+ cells grown under hypoxic/normoxic conditions. Group G/H, CD133+ ${ }^{+}$IF-siRNA cells grown under hypoxic/normoxic conditions. 
A
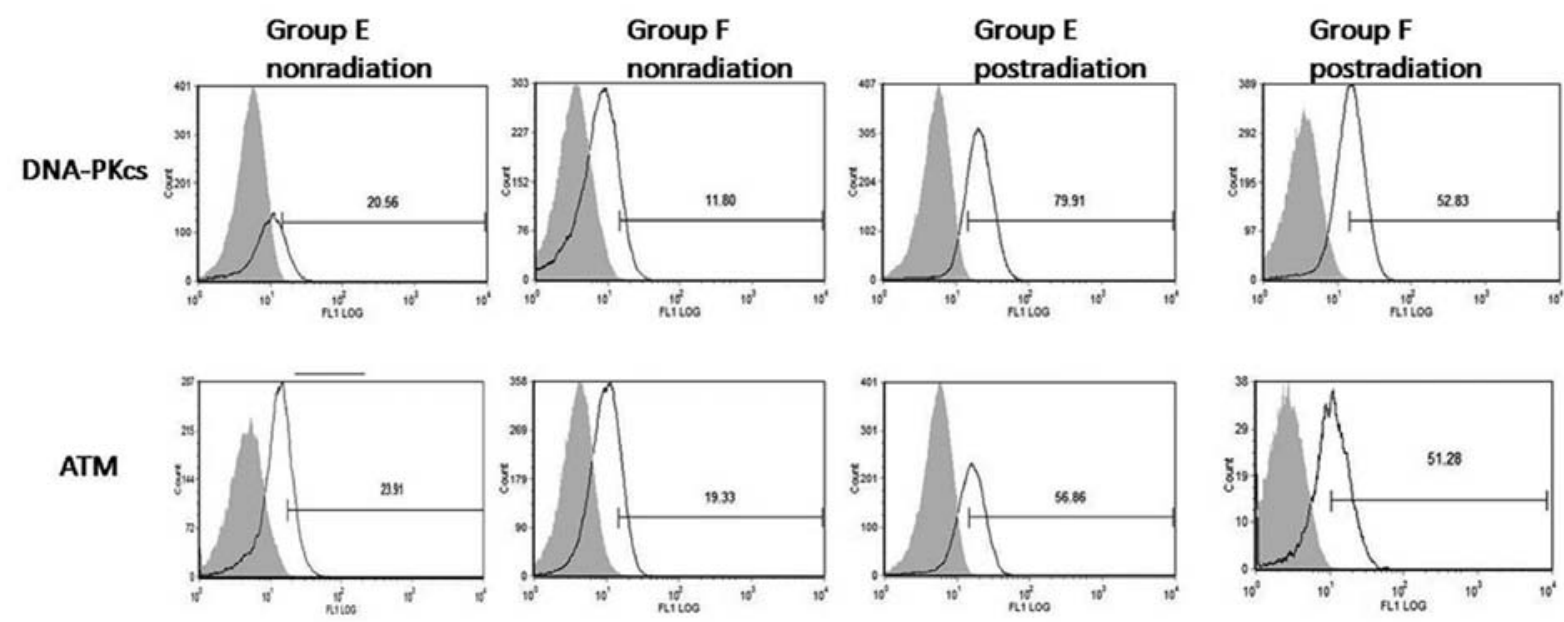

P53
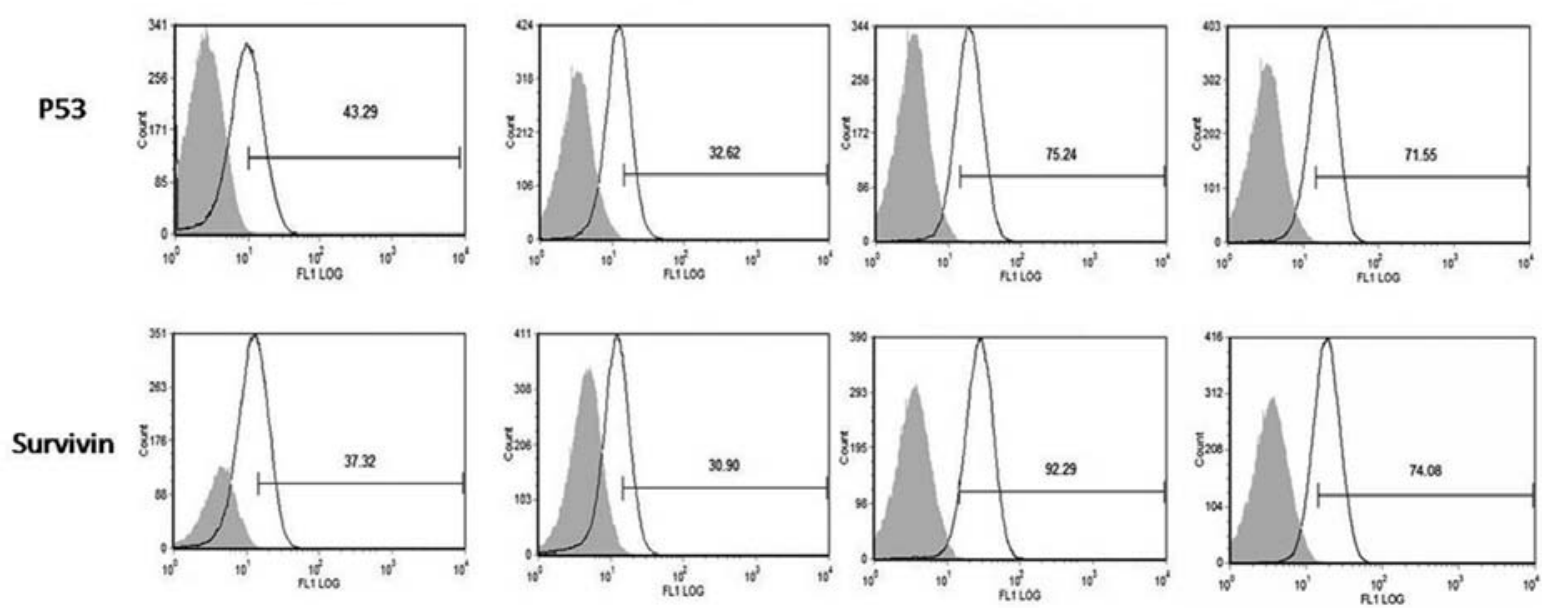

B
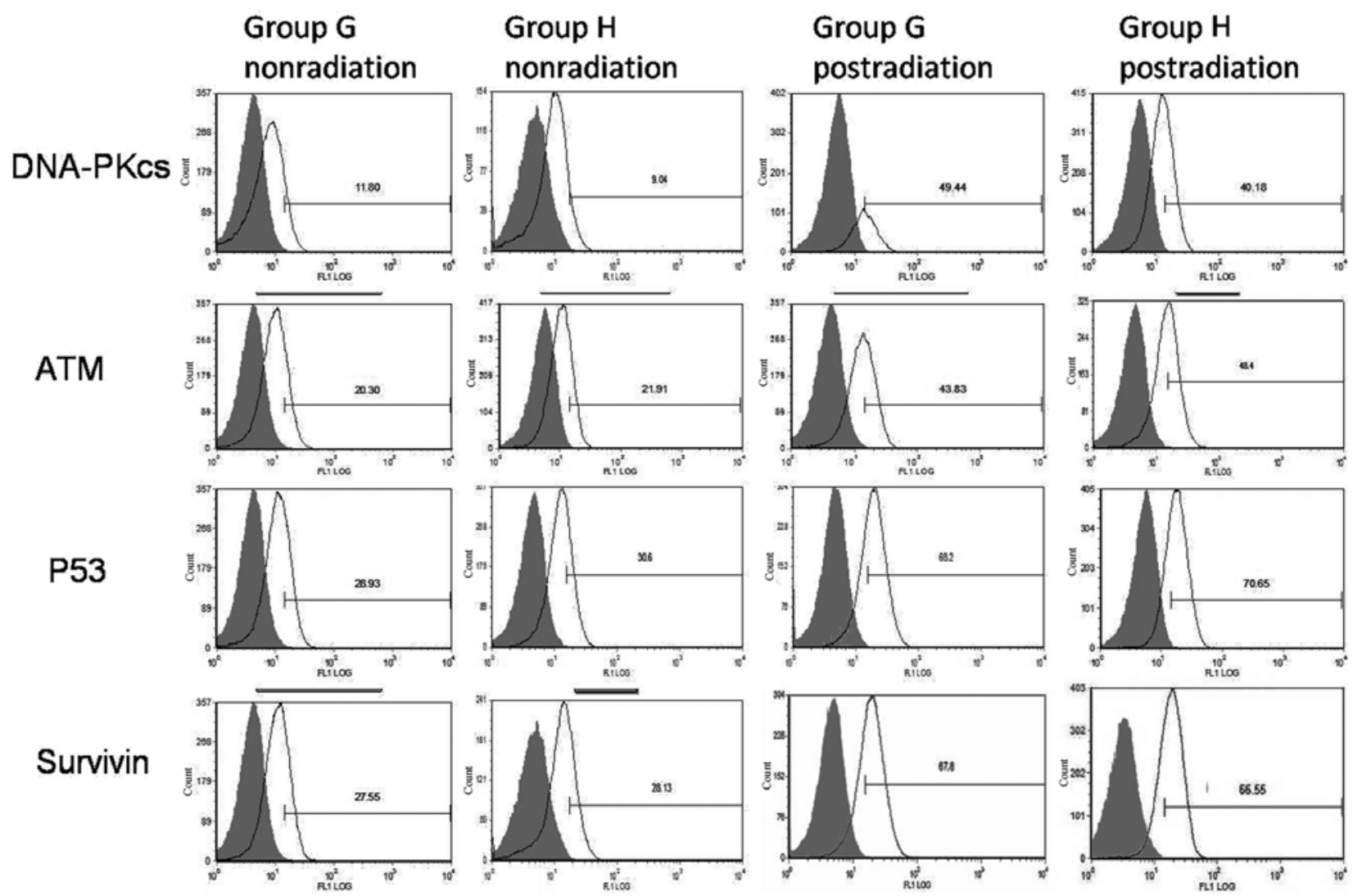

Figure 7. Protein expression of DNA-PKcs, ATM, survivin and $\mathrm{p} 53$ was detected in CD133+ cells using fluorescence-activated flow cytometry. The expression levels of all four proteins were higher in $\mathrm{CD}_{133^{+}}$cells than in $\mathrm{CD} 133^{-}$cells following irradiation $(\mathrm{P}<0.01)$. In addition, expression of DNA-PKcs and survivin in group $\mathrm{E}$ was higher than in the other three groups following irradiation $(\mathrm{P}<0.05)$, while levels of ATM and $\mathrm{p} 53$ did not increase significantly $\mathrm{P}>0.05)$. 
HIF-1 $\alpha$ induced by hypoxia could potentially promote the proliferation of $\mathrm{CD} 33^{+}$cells, leading to increased radioresistance by group $\mathrm{A}$.

The observation that levels of $\mathrm{CD} 133^{+}$cells increased for all four groups $24 \mathrm{~h}$ after a $10 \mathrm{~Gy}$ radiation dose, then decreased in a radiation dose and time-dependent manner, revealed that $10 \mathrm{~Gy}$ of radiation could induce the greatest killing effect to CD133 cells. In contrast, the same dose did not seem to affect the majority of $\mathrm{CD} 33^{+}$. However, when larger doses of radiation were administered, a greater proportion of $\mathrm{CD} 133^{+}$ cells were killed, resulting in an increase in growth inhibition ratios. Moreover, $24 \mathrm{~h}$ after irradiation, the greatest change in growth inhibition ratios was observed, suggesting that CD133 cells were killed, resulting in an increase in the percentage of $\mathrm{CD}_{133^{+}}$cells remaining. Subsequently, $\mathrm{CD} 133^{+}$cells began to proliferate and differentiate into $\mathrm{CD} 133^{-}$cells. As a result, both the ratio of $\mathrm{CD}_{133^{+}}$cells and the associated growth inhibition ratio, decreased. Taken together, these observations suggest that $\mathrm{CD} 133^{+}$cells possess a radioresistant capacity and hypoxia enhances this property.

To investigate possible mechanism(s) of radioresistance by CSCs and the role of hypoxia in this process, CD133 ${ }^{+} \mathrm{Hep}-2$ cells were isolated and cultured in SFM. Sphere forming assays have been performed to characterize the self-renewal capacity of CSCs in a variety of studies and cells that are able to form spheres are widely regarded as CSCs (29-33). In the present study, spheres formed in SFM within a week and subsequently increased in size. When the purity of these spheres was checked by flow cytometry, the percentage of $\mathrm{CD} 133^{+}$cells was $92.8 \%$ and 2 weeks later, was $88.3 \%$. These results indicate that most of the $\mathrm{CD} 133^{+}$cells had not differentiated. Furthermore, 2 weeks after $\mathrm{CD} 133^{+}$cells received a dose of radiation (10 Gy), the growth inhibition ratio for hypoxic Hep-2 cells (group A) was lower than that of the other three groups. Based on these results, we hypothesize that hypoxia enhances the radioresistance of $\mathrm{CD}_{133^{+}}$cells and the results of the sphere formation assays performed using $\mathrm{CD} 133^{+}$cells support this hypothesis.

To investigate potential mechanisms for the radioresistant phenotype associated with Hep-2 cells, expression levels of DNA-PKcs, ATM, survivin and p53 were detected in CD133+ cells before and after treatment with radiation. DNA-PKcs and ATM represent key enzymes in two DNA repair pathways, DNA nonhomologous end-joining (NHEJ) and homologous recombination (HR), respectively. Both proteins belong to the family of PI3K protein kinases and DNA-PK initiates the process of DNA repair (34), while ATM responds to DNA damage by phosphorylating cell cycle regulating kinases such as Chk1 and Chk2 (35). Survivin is an anti-apoptosis gene whose activation and distribution are also affected by DNA-PK and ATM and survivin has been found to have an important role in the generation and development of tumors (36). p53 is an anti-oncogene that has been shown to inhibit tumor invision via the formation of the complex, wtp53-MDM2-Slug (37). However, mutated p53 mediates the opposite effect and in this study, mutated p53 (DO-1) was detected. Expression levels for these four proteins detected in groups E-H were higher following irradiation and were higher compared to levels detected in CD133 cells. These results suggest that DNA damage repair in $\mathrm{CD}_{133^{+}}$cells is more active, consistent with the radioresistance exhibited by $\mathrm{CD} 133^{+}$cells.
Following irradiation, cells arrested in the G1 phase and a checkpoint response was initiated. When ATM is activated, Chk1 and Chk2 are subsequently activated to repair injured DNA. Furthermore, p53 is affected by ATM. Therefore, the increase in levels of mutated p53 could have weakened the inhibition of survivin, thereby leading to increased expression of survivin. In addition, DNA-PK and ATM also have the capacity to increase expression of survivin. With higher levels of survivin and mutated p53 present in Hep-2 cells, apoptosis would be inhibited. After irradiation, expression of DNA-PKcs and survivin in hypoxic Hep-2 cells (group E) was found to be higher than in the other three groups. In contrast, levels of ATM and p53 appeared unchanged. Taken together, these results indicate that under hypoxic conditions, enhanced DNA repair mediated by NHEJ was activated and DNA-PK played a key role.

In conclusion, $\mathrm{CD}_{133^{+}}$cells exhibit characteristics of cancer stem cells, namely the ability to become tumor cells, the capacity for self-renewal and the ability to undergo differentiation and thus, have the potential to play a key role in the radioresistant phenotype of Hep-2 cells. Furthermore, radioresistance of $\mathrm{CD}_{133^{+}}$cells was enhanced by hypoxic conditions and was associated with an increase in DNA-PK activity. These results suggest that the NHEJ pathway of DNA repair is a mechanism that contributes to the radioresistant phenotype exhibited by laryngeal carcinomas.

\section{Acknowledgements}

The technical assistance of Professor Yong Zhao and Hongran Li (State Key Laboratory of Biomembrane and Membrane Biotechnology, Chinese Academy of Sciences) is highly acknowledged. This study was supported by The Jieping Wu Medicine Foundation of China (grant 320.6750.10121).

\section{References}

1. Nix P, Greenman J, Cawkwell L and Stafford N: Radioresistant laryngeal cancer: beyond the TNM stage. Clin Otolaryngol Allied Sci 29: 105-114, 2004.

2. Velasco-Velázquez M, Homsi N, De L and Pestell R: Breast cancer stem cells. Int J Biochem Cell Biol 44: 573-577, 2012.

3. Vaiopoulos A, Kostakis I, Koutsilieris M and Papavassiliou A: Colorectal cancer stem cells. Stem Cells 30: 363-371, 2012.

4. Guerrero-Cazares H, Attenello FJ and Quinones-Hinojosa A: Stem cells in gliomas. Handb Clin Neurol 104: 63-73, 2012.

5. Mannelli G and Gallo O: Cancer stem cells hypothesis and stem cells in head and neck cancers. Cancer Treat Rev 38: 515-539, 2012.

6. Tu S and Lin S: Prostate cancer stem cells. Clin Genitourin Cancer 10: 69-76, 2012.

7. Singh S, Hawkins C, Clarke I, et al: Identification of human brain tumour initiating cells. Nature 432: 396-401, 2004.

8. Chen Y, Hsu H, Chen Y, et al: Oct-4 expression maintained cancer stem-like properties in lung cancer-derived CD133-positive cells. PLoS One 3: e2637, 2008.

9. Hermann P, Huber S, Herrler T, et al: Distinct populations of cancer stem cells determine tumor growth and metastatic activity in human pancreatic cancer. Cell Stem Cell 1: 313-323, 2007.

10. Ma S, Chan K, Lee T, et al: Aldehyde dehydrogenase discriminates the CD133 liver cancer stem cell populations. Mol Cancer Res 6: 1146-1153, 2008.

11. Miki J, Furusato B, Li H, et al: Identification of putative stem cell markers, CD133 and CXCR4, in hTERT-immortalized primary nonmalignant and malignant tumor-derived human prostate epithelial cell lines and in prostate cancer specimens. Cancer Res 67: 3153-3161, 2007. 
12. Zhang Q, Shi S, Yen Y, Brown J, Ta J and Le A: A subpopulation of CD133 (+) cancer stem-like cells characterized in human oral squamous cell carcinoma confer resistance to chemotherapy. Cancer Lett 289: 151-160, 2009.

13. Matsumoto K, Arao T, Tanaka K, et al: mTOR signal and hypoxia inducible factor-1 alpha regulate CD133 expression in cancer cells. Cancer Res 69: 7160-7164, 2009.

14. Wei X, Zhou L, Cheng L and Tian J: Experimental investigation of CD133 as a putative marker of tumor-initiating cell in laryngeal carcinoma. Chin J Otorhinolaryngol Head Neck Surg 41: 940-944, 2006.

15. Ailles L and Weissman I: Cancer stem cells in solid tumors. Curr Opin Biotechnol 18: 460-466, 2007.

16. Bao S, Wu Q, McLendon R, et al: Glioma stem cells promote radioresistance by preferential activation of the DNA damage response. Nature 444: 756-760, 2006.

17. Liu G, Yuan X, Zeng Z, et al: Analysis of gene expression and chemoresistance of $\mathrm{CD} 133^{+}$cancer stem cells in glioblastoma. Mol Cancer 5: 67, 2006

18. Nie D: Cancer stem cell and niche. Front Biosci (Schol Ed) 2: 184-193, 2010

19. Iwasaki H and Suda T: Cancer stem cells and their niche. Cancer Sci 100: 1166-1172, 2009.

20. Julie B, Sneddon and Zena W: Location, location, location: the cancer stem cell niche. Cell Stem Cell 1: 607-611, 2007.

21. McCord A, Jamal M, Shankavaram U, Lang F, Camphausen K and Tofilon P: Physiologic oxygen concentration enhances the stem-like properties of $\mathrm{CD}_{133^{+}}$human glioblastoma cells in vitro. Mol Cancer Res 7: 489-497, 2009.

22. Mazumdar J, Dondeti V and Simon M: Hypoxia-inducible factors in stem cells and cancer. J Cell Mol Med 13: 11-12, 2009.

23. Kessler J, Hahnel A, Wichmann H, et al: HIF-1alpha inhibition by siRNA or chetomin in human malignant glioma cells: effects on hypoxic radioresistance and monitoring via CA9 expression. BMC Cancer 10: 605, 2010.

24. Wei X, Zhou L, Cheng L, Tian J, Jiang J and Maccallum J: In vivo investigation of CD133 as a putative marker of cancer stem cells in Hep-2 cell line. Head Neck 31: 94-101, 2009.

25. Patrawala L, Calhoun T, Schneider-Broussard R, Zhou J, Claypool K and Tang D: Side population is enriched in tumorigenic, stemlike cancer cells, whereas $\mathrm{ABCG}^{+}$and ABCG2-cancer cells are similarly tumorigenic. Cancer Res 65: 6207-6219, 2005.
26. Kondo T, Setoguchi T and Taga T: Persistence of a small subpopulation of cancer stem-like cells in the C6 glioma cell line. Proc Natl Acad Sci USA 101: 781-786, 2004.

27. Soeda A, Park M, Lee D, et al: Hypoxia promotes expansion of the CD133-positive glioma stem cells through activation of HIF-1alpha. Oncogene 28: 3949-3959, 2009.

28. Hashimoto O, Shimizu K, Semba S, et al: Hypoxia induces tumor aggressiveness and the expansion of CD133-positive cells in a hypoxia-inducible factor- $1 \alpha$-dependent manner in pancreatic cancer cells. Pathobiology 78: 181-192, 2011.

29. Wicha M: Hedgehog signaling and Bmi-1 regulate self-renewal of normal and malignant human mammary stem cells. Cancer Res 66: 6063-6071, 2006.

30. Diamandis P, Wildenhain J, Clarke I, et al: Chemical genetics reveals a complex functional ground state of neural stem cells. Nat Chem Biol 3: 268-273, 2007.

31. Beier D, Hau P, Proescholdt M, et al: CD133 (+) and CD133 (-) glioblastoma-derived cancer stem cells show differential growth characteristics and molecular profiles. Cancer Res 67: 4010-4015, 2007.

32. Ponti D, Costa A, Zaffaroni N, et al: Isolation and in vitro propagation of tumorigenic breast cancer cells with stem/progenitor cell properties. Cancer Res 65: 5506-5511, 2005.

33. Yu F, Yao H, Zhu P, et al: let-7 regulates self renewal and tumorigenicity of breast cancer cells. Cell 131: 1109-1123, 2007.

34. Dobbs T, Tainer J and Lees-Miller S: A structural model for regulation of NHEJ by DNA-PKcs autophosphorylation. DNA Repair 9: 1307-1314, 2010.

35. Tomita M: Involvement of DNA-PK and ATM in radiation- and heat-induced DNA damage recognition and apoptotic cell death. J Radiat Res 51: 493-501, 2010.

36. Asumen M, Ifeacho T, Cockerham L, Pfandl C and Wall N: Dynamic changes to survivin subcellular localization are initiated by DNA damage. Onco Targets Ther 3: 129-137, 2010.

37. Wang S, Wang W, Chang Y, et al: p53 controls cancer cell invasion by inducing the MDM2-mediated degradation of Slug. Nat Cell Biol 11: 694-705, 2009.

38. Qu Y, Li X, Xu O, Wang M and Lu X: Impacts of hypoxia on the features and chemoresistance of cancer stem cells in Hep-2 cells and underlying mechanism. Chin J Otorhinolaryngol Head Neck Surg 47: 228-233, 2012. 